\title{
Waste Classification Assessment of Nuclear Steels for Fusion Power Applications
}

\author{
G.W. Bailey, M.R. Gilbert, and O Vilkhivskaya \\ UK Atomic Energy Authority \\ Culham Science Centre, Abingdon, Oxon, OX14 3DB, UK \\ greg.bailey@ukaea.uk,mark.gilbert@ukaea.uk, olga.vilkhivskaya@ukaea.uk
}

\begin{abstract}
Fusion power is an attractive option for the world's future energy needs. An important goal for fusion is to avoid the severe radioactive waste issues associated with nuclear fission. However, the neutrons produced in the fusion plasma reaction impinge on the surrounding reactor structure causing nuclear activation. It is hoped that activated material from fusion facilities can be disposed of as low level waste 50-100 years after operation ceases, but recent work suggests this may be difficult to achieve. This work presents inventory simulations for a number of potential fusion steels, for two neutron irradiation conditions typical of the DEMO reactor concept. The results are used to determine if the steels meet low level waste regulations, for a number of different international waste management systems. These results show that steels do not appear able to consistently meet low level waste requirements when exposed to near-plasma neutron fluxes. They have more success when exposed to lower fluxes, but traditional steels will still struggle to meet low level waste requirements in a fusion environment.
\end{abstract}

KEYWORDS: Fusion, Steel, Waste, Activation

\section{INTRODUCTION}

Nuclear fusion is promised to be near perfect energy source: abundant energy from readily available fuel. However the radioactive waste expected to be produced from fusion facilities is often overlooked. Future facilities will use deuterium-tritium fusion as an energy source, the major energy carriers from this are neutrons emitted at $14 \mathrm{MeV}$. These neutrons, not confined to the fusion plasma, impinge on the surrounding reactor components causing nuclear reactions and thus activating the materials. Many of the created radionuclides are sufficiently long-lived that they will be present at reactor end-of-life (EOL), meaning such materials will need to be disposed of as radioactive waste.

All radioactive waste from fusion reactors is hoped to be classified as low level waste (LLW) 50 to 100 years after EOL. Recent work using models of the European DEMO fusion reactor concept, suggest that vast quantities of material, mostly the structural steels, will struggle to be classified as LLW for over 1000 years [1-3]. These studies show that the production of long-lived (half life, $t_{1 / 2}$, from 500 years to $>1 \times 10^{5}$ years) nuclides will prevent steels from achieving LLW requirements. These works used the waste disposal criteria of the UK and France and only considered materials 
which are planned to be used in the construction of the next step DEMOstration power plant being designed in Europe.

Given the unavoidable nature of radioactive waste from fusion, a detailed understanding of the waste classification behaviour of steels under expected fusion irradiations and knowledge of the differing radioactive waste disposal regulations used is required. This study investigates the waste expectations of a number of steels which could see use in fusion power plants by performing detailed inventory simulations for irradiation conditions typical of a DEMO-like reactors. The LLW waste criteria of 5 regulatory systems, UK, Spain, Japan, USA and Russia, have been applied to these results to understand how the different steels perform from a waste classification view point. The inventory simulations have been performed using FISPACT-II [4] and the most recent TENDL 2017 nuclear data library [5] and UK decay 2012 decay data library.

\section{International LLW Regulations and Classifications}

What requirements a given sample must meet to be classified as LLW is not a rigorously defined set of parameters; waste disposal regulations differ between countries and repositories. It is entirely possible that the same sample would receive different waste classifications in different countries and be subject to different methods of disposal. To quantify the waste prospect of fusion steels several of these regulatory systems need to be investigated; this study will compare the LLW classification regimes from the UK, Spain, Japan, USA and Russia. Waste is classified based on material specific activity (activity per unit mass or volume) of global sources, such as total $\alpha$ or $\beta$ activity and/or that from a given set of radionuclides. While some nuclides will be common to several systems, others may be excluded. Details of each regime studied are presented in table 1, alongside a selection of limits from activity sources which previous work [1] has identified as waste critical. It should be noted that the information presented in table 1 is incomplete in terms of the details required for full waste assessment. The non-UK waste classifications include limits for more nuclides than those listed in table 1 and may contain lower limits for very low level classification.

\section{Fusion Steels under Study}

Steels used in nuclear environments can be divided into two distinct categories: those designed for irradiation exposure and those which weren't. The steels expected to be irradiated are developed for reduced activation via the minimising of impurities and reduction of elements with known problem isotopes. These Reduced Activation Ferritic/Martensitic (RAFM) steels should show the greatest adherence to LLW criteria, and will be used for in-vessel components, which are exposed to the highest neutron fluxes. Non-RAFM steels will be used in lower flux regions such as the vacuum vessel and ex-vessel components. Table 2 details the steels studied and their elemental composition can be found in APPENDIX A. It should be noted that most of the RAFM materials are not mass produced (they are experimental or under-development at time of writing), as such the compositions for these materials given in APPENDIX A should be considered as lab-based idealised results. 
Table 1: The regulations and a selection of limits of waste relevant nuclides for the waste classification systems used in this study.

\begin{tabular}{|c|c|c|c|c|c|c|}
\hline Country & \multicolumn{6}{|c|}{ Regulations } \\
\hline $\begin{array}{l}\text { UK }[6,7] \\
\text { Spain }[8] \\
\text { Russia [9] } \\
\text { USA [10,11] } \\
\text { Japan [12] }\end{array}$ & \multicolumn{6}{|c|}{$\begin{array}{l}\text { Global limits on total } \alpha \text { and } \beta+\gamma \text { activity. } \\
\text { Limits on } \alpha, \beta+\gamma \text { and } 31 \text { nuclide activities. } \\
\text { Limits on }{ }^{3} \mathrm{H},\left(\beta+\gamma-{ }^{3} \mathrm{H}\right) \text { and } \alpha \text {. Extra } 9 \text { nuclide limits for mixed samples } \\
\text { Imposes limits on } 10 \text { nuclide activities and transuranic nuclides. } \\
\text { Activity limits on } 6 \text { nuclides and global } \alpha \text { activity. }\end{array}$} \\
\hline \multirow[b]{2}{*}{ Country } & \multicolumn{6}{|c|}{ Maximal Limits $\left.(\mathrm{Bq} / \mathrm{g}){ }^{\dagger}\left(\mathrm{Bq} / \mathrm{m}^{3}\right)\right]$} \\
\hline & $\alpha$ & $\beta+\gamma$ & ${ }^{3} \mathrm{H}$ & ${ }^{14} \mathrm{C}$ & ${ }^{63} \mathrm{Ni}$ & ${ }^{94} \mathrm{Nb}$ \\
\hline $\begin{array}{l}\text { UK }[6,7] \\
\text { Spain [8] } \\
\text { Russia [9] } \\
\text { USA [10,11] } \\
\text { Japan [12] }\end{array}$ & $\begin{array}{l}4 \times 10^{3} \\
3.7 \times 10^{3} \\
1 \times 10^{3} \\
\quad- \\
1 \times 10^{5}\end{array}$ & $\begin{array}{l}1.2 \times 10^{4} \\
3.7 \times 10^{4} \\
1 \times 10^{4 *} \\
\quad- \\
-\end{array}$ & $\begin{aligned} 1 \times 10^{6} \\
1 \times 10^{8} \\
1.48 \times 10^{12 \dagger} \\
\quad-\end{aligned}$ & $\begin{array}{c}- \\
2 \times 10^{5} \\
3 \times 10^{12 \dagger} \\
2.96 \times 10^{11 \dagger} \\
1 \times 10^{10}\end{array}$ & $\begin{array}{c}- \\
1.2 \times 10^{7} \\
2.6 \times 10^{14 \dagger} \\
1.23 \times 10^{12 \dagger} \\
1 \times 10^{7}\end{array}$ & $\begin{array}{c}- \\
1.2 \times 10^{2} \\
7.4 \times 10^{9 \dagger} \\
7.4 \times 10^{8 \dagger} \\
-\end{array}$ \\
\hline
\end{tabular}

${ }^{*}$ The Russian criteria subtracts ${ }^{3} \mathrm{H}$ activity from $\beta+\gamma$ activity before the limit is applied.

\section{Inventory Simulations}

The results of inventory simulations performed with FISPACT-II and the TENDL 2017 nuclear data library, which is accepted by the EUROfusion collaboration for activation calculations, are used to classify the steels in the regulatory systems given in table 1 . The simulations used irradiation scenarios typical of two regions of the DEMO reactor [1]. As the steels that will be a primary waste concern are those closest to the plasma, the calculations have been performed for conditions representative of DEMO's blanket and Vacuum Vessel (VV). The neutron flux spectra used are taken from a MCNP [19,20] model of the DEMO [21] reactor concept, which was developed by the EUROfusion collaboration; these are shown in figure 1. Comparing the spectra in figure 1 it is clear that the blanket materials will experience the greatest fluxes and thus are expected to have the highest levels of activation, under identical irradiation scenarios. The time-scales used were chosen to match the expected operational time-scales of DEMO. As a consequence of this, the blanket and VV scenarios will be different. Over DEMO's expected lifespan the VV will never be replaced but the blankets will be replaced after the first phase of operation. Calculations were performed from the start the component's life until 1000 years after EOL of DEMO.

The irradiation schedules used have been developed to best replicate the operational life time of a DEMO reactor. These feature periods of neutron irradiation for extended periods of low power and rapid pulses of full power operation. Cooling periods, times when no flux is present, are also included representing reactor maintenance periods and down time. This careful choice of irradiation and cooling allow long and short lived nuclide populations expected to present at EOL to be accurately reproduced. 
Table 2: A description of the steels studied separated between RAFM and non-RAFM.

\begin{tabular}{|c|c|}
\hline \multicolumn{2}{|r|}{ Non-RAFM Steels } \\
\hline Steel & Description \\
\hline $\begin{array}{l}\text { SS316 } \\
\text { Steel } 660 \\
\text { XM19 } \\
\text { Inconel } 718 \\
\text { G91 }\end{array}$ & $\begin{array}{l}\text { A standard molybdenum-bearing grade austenitic stainless steel. } \\
\text { A precipitation hardening austenitic stainless steel. } \\
\text { A Nitrogen strengthened austenitic steel. } \\
\text { A gamma double prime strengthened austenitic nickel-chromium-based steels. } \\
\text { Ferritic-martensitic steel micro-alloyed with } \mathrm{V} \text { and } \mathrm{Nb} \text {, available in two types. }\end{array}$ \\
\hline \multicolumn{2}{|r|}{ RAFM Steels } \\
\hline Steel & Description \\
\hline $\begin{array}{l}\text { Eurofer } \\
\text { Hiperfer } \\
\text { Rusfer } \\
\text { CLAM } \\
\text { F82H }\end{array}$ & $\begin{array}{l}\text { European RAFM steel developed for nuclear power applications [13]. } \\
\text { High Performance Ferrite is a German developed RAFM steel [14]. } \\
\text { Referred to as EK-181, a RAFM steel developed in the Russian Federation [15]. } \\
\text { China Low Activation Martensitic (CLAM) steel [16] developed at the Institute } \\
\text { of Nuclear Energy Safety Technology (INEST). } \\
\text { Developed by the Japan Atomic Energy Research Institute (JAERI) [17], modi- } \\
\text { fied composition developed by an International Energy Agency (IAE) collabora- } \\
\text { tion [18]. }\end{array}$ \\
\hline
\end{tabular}

\section{Waste Classification Analysis}

\subsection{Waste Classification from Global Specific Activity}

It was found that no steel produced any $\alpha$ activities above $10^{-1} \mathrm{~Bq} / \mathrm{kg}$ from 1 year after EOL, which is significantly lower than any $\alpha$ limit in table 1 , showing that $\alpha$ activity is not a concern for fusion steel waste. Figure 2 shows the $\beta+\gamma$ activity for the steels studied for times after EOL. A single blanket steel, F82H, is able to meet the Spanish $\beta+\gamma, 500$ years after EOL, and no steel meets the UK limit. It can be concluded that no steel, under DEMO blanket irradiation conditions can be classified as UK LLW. For VV results, left panel of figure 2, only Inconel 718 fails to reach either of the LLW limits (for Spain and UK) shown. Breaching Spain's $\beta+\gamma$ limit only prevents a sample from achieving a higher grade of LLW classification, not LLW classification entirely, other factors such as specific nuclide activities need to be considered. It is desired that steels be LLW after 100 years, at this time all of the RAFM steels have activities below the UK limit, as well as G91-type 2, and G91-type 1 almost meeting the limit. These steels could be UK LLW, but may not have the mechanical properties required of VV steel. Due to the temperature and weak magnetic properties required for VV steels they will have to be austenitic. Reduced activation steels are typically ferritic or martensitic so may not be best suited to use in the VV. 


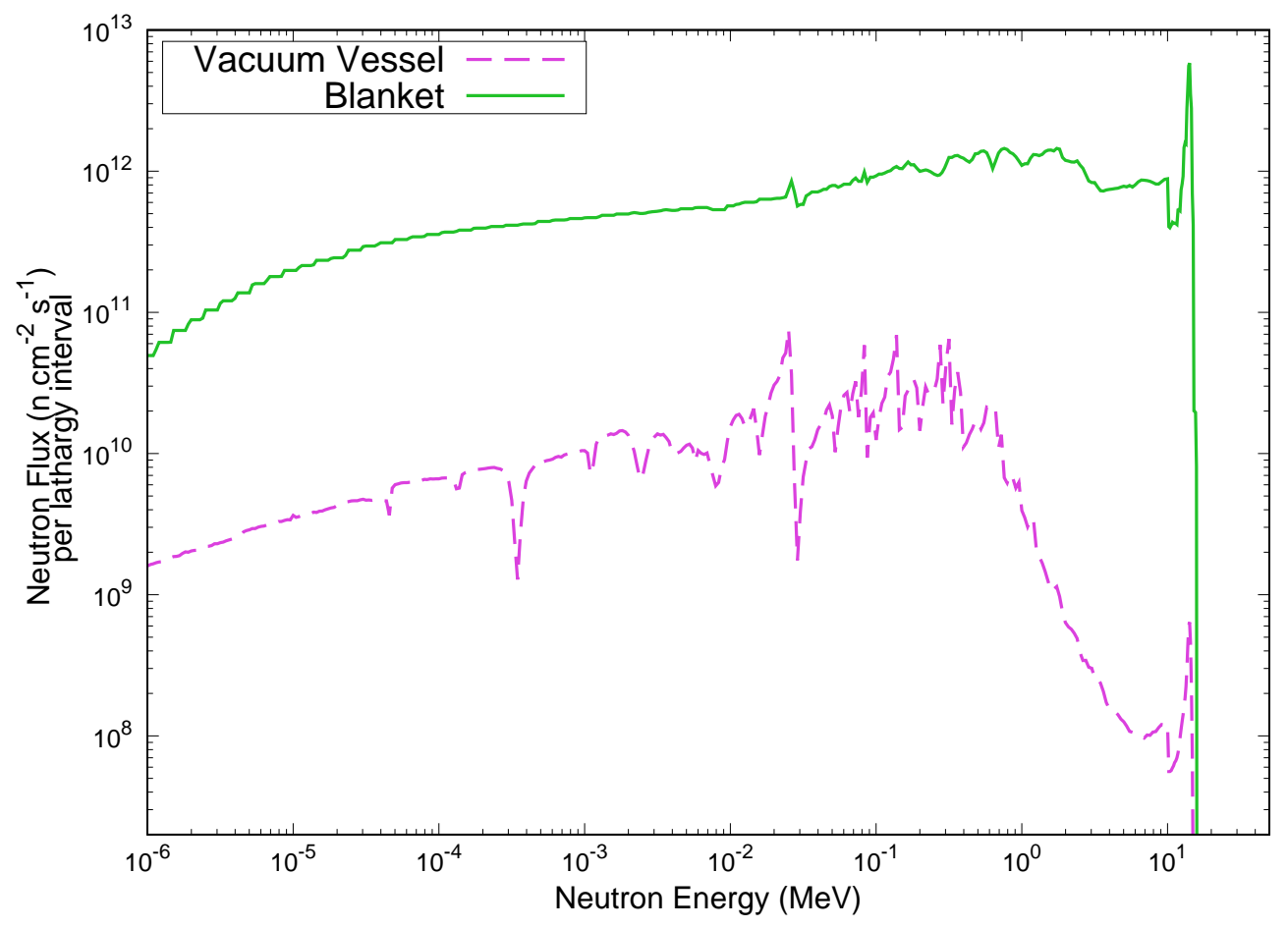

Figure 1: Neutron flux spectra used in the inventory simulations detailed in this work. The spectra were found using the Monte Carlo Transport code MCNP [19,20].

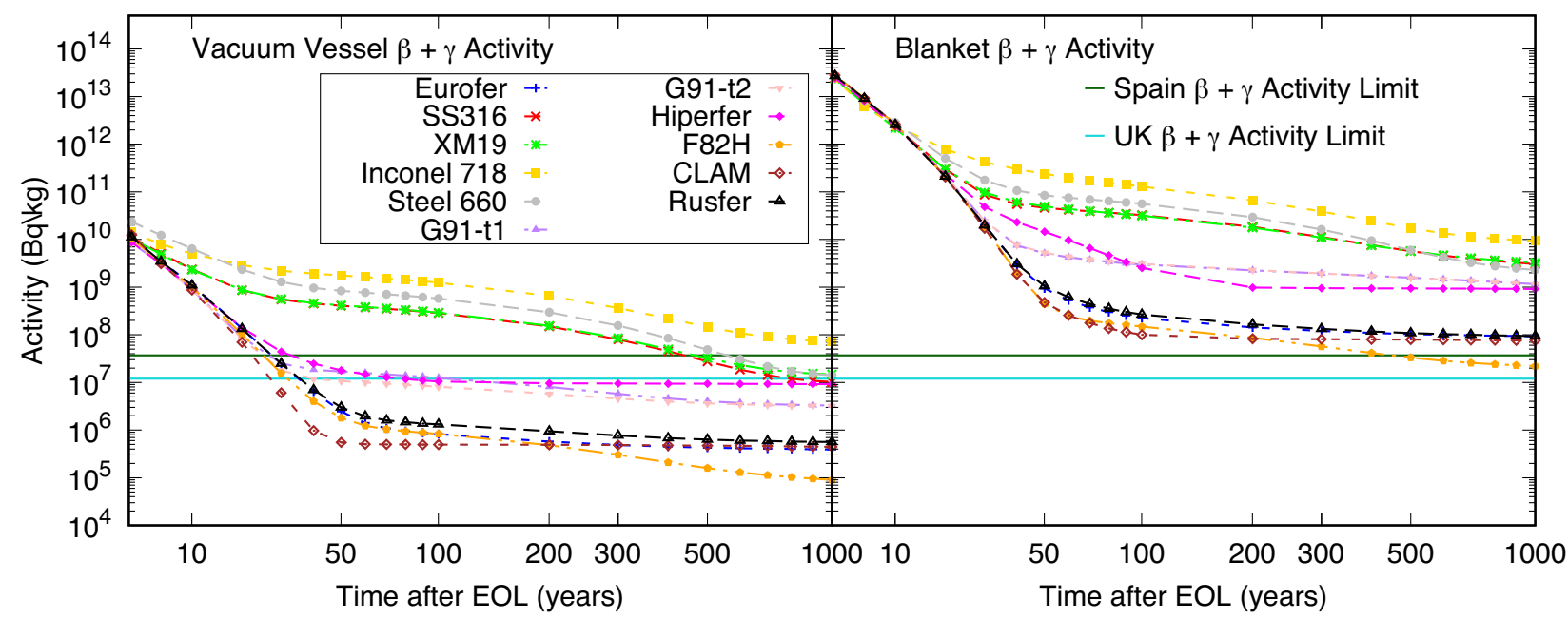

Figure 2: $\beta+\gamma$ activities for the steels studied. The left panels show the VV results, the right the blanket.

\subsection{Waste Classification from Nuclide Specific Activity}

To explore some nuclides of primary concern to long term waste classification, the activities of ${ }^{14} \mathrm{C}$ and ${ }^{94} \mathrm{Nb}$ in each steel are shown in figure 3 alongside the limits from the LLW regulations. 
Japan's ${ }^{14} \mathrm{C}$ is not presented as it is larger than the scale plotted, all steels meet this requirement. In the blanket, right panels, only F82H steel meets any ${ }^{94} \mathrm{Nb}$ limits, but most do meet the Spanish ${ }^{14} \mathrm{C}$ limit. The UK's LLW criteria does not include any limits on specific nuclide activities. This is confirmation of what was suggested by figure 2; few steels will classify as LLW on after 100 years when exposed to DEMO's blanket irradiation conditions and the blanket will be a major contributor to waste. As CLAM's composition does not contain any $\mathrm{Nb}$ or Mo impurities (see APPENDIX A) it does not produce any ${ }^{94} \mathrm{Nb}$. While this is a positive result for this study, CLAM is an experimental material whose composition may alter with mass production. The VV results are more promising from a waste disposal perspective: all steels show ${ }^{14} \mathrm{C}$ activities below the limits plotted and 4 steels meet all ${ }^{94} \mathrm{Nb}$ limits. This should mean that more steels should be able to be called LLW when exposed to VV conditions, when compared to the blanket classifications.

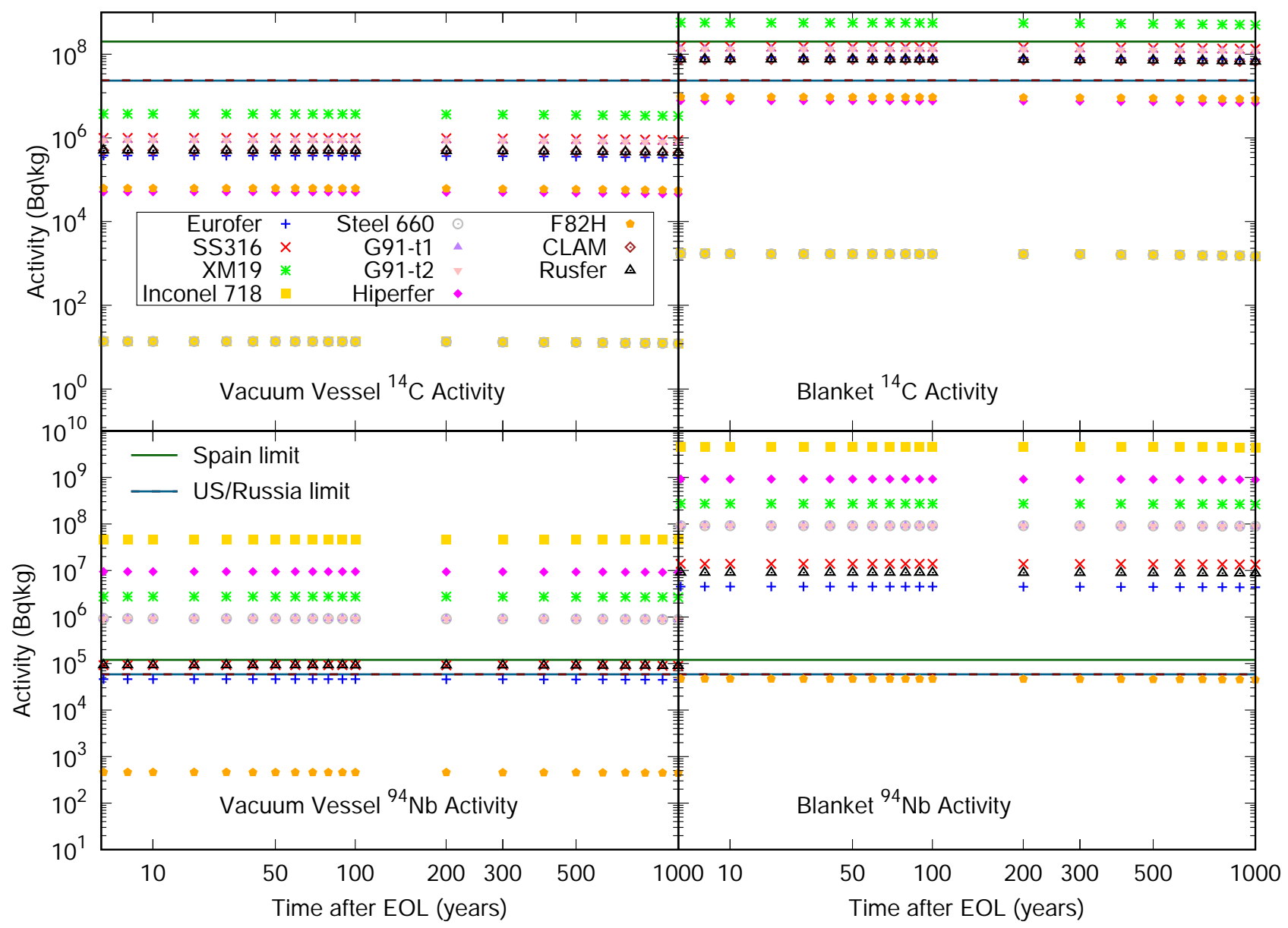

Figure 3: The activity from ${ }^{14} \mathrm{C}$ (upper) and ${ }^{94} \mathrm{Nb}$ (lower). Right panels show results for the blanket, left for the VV. The Russia and US limits are indistinguishable (table 1). 


\section{LLW Classifications}

When determining whether a steel can be classified as LLW all of a regulatory system's requirements were considered, not just those presented in table 1 . This can mean a vast array of other factors need to be included, such as accounting for a mixed sample, and often waste systems have multiple LLW classifications. For the purpose of this work, steels will be classified as LLW or ILW, a more detailed breakdown of waste classification will be left for future work. The final waste classifications of the steels studied at 100 years after EOL are shown in table 3.

Table 3: Waste classifications for the steels studied for each set of waste disposal criteria.

\begin{tabular}{|l|ccccc|ccccc|}
\hline \multirow{3}{*}{ Steel } & \multicolumn{5}{|c|}{ Blanket } & \multicolumn{5}{c|}{ Vacuum Vessel } \\
\cline { 2 - 8 } & UK & US & Spain & Russia & Japan & UK & US & Spain & Russia & Japan \\
\hline SS316 & ILW & ILW & ILW & ILW & LLW & ILW & LLW & LLW & ILW & LLW \\
Steel 660 & ILW & ILW & ILW & ILW & LLW & ILW & ILW & ILW & ILW & LLW \\
XM19 & ILW & ILW & ILW & ILW & LLW & ILW & ILW & ILW & ILW & LLW \\
Inconel 718 & ILW & ILW & ILW & ILW & LLW & ILW & ILW & ILW & ILW & LLW \\
G91 type 1 & ILW & ILW & ILW & ILW & LLW & ILW & LLW & ILW & LLW & LLW \\
G91 type 2 & ILW & ILW & ILW & ILW & LLW & LLW & LLW & ILW & LLW & LLW \\
Eurofer & ILW & ILW & ILW & ILW & LLW & LLW & LLW & LLW & LLW & LLW \\
Hiperfer & ILW & ILW & ILW & ILW & LLW & LLW & ILW & ILW & ILW & LLW \\
Rusfer & ILW & ILW & ILW & ILW & LLW & LLW & LLW & LLW & LLW & LLW \\
CLAM & ILW & LLW & LLW & ILW & LLW & LLW & LLW & LLW & LLW & LLW \\
F82H & ILW & LLW & LLW & ILW & LLW & LLW & LLW & LLW & LLW & LLW \\
\hline
\end{tabular}

\section{CONCLUSIONS}

This work has shown that LLW classification requirements can differ globally. This has important consequences for fusion steels as they are desired to achieve LLW status 50-100 years after a fusion reactors EOL. Table 3 shows that this is difficult for any of the steels studied to achieve when exposed to the irradiation conditions expected of the blankets in a DEMO reactor. The steels CLAM and F82H perform the best but are unable to meet LLW classification in all waste systems. Steels are more successful at meeting LLW requirements in the VV, here F82H, CLAM, Eurofer and Rusfer should meet LLW specifications for all systems. Unfortunately, these RAFM steels will likely not have the structural qualities to meet the requirements of VV construction. Of the non-RAFM steels the G91 types show the best waste behaviour (type 2 specifically due to lower Ni content), but cannot be guaranteed to meet LLW criteria within the specified time frame. Japan's LLW criteria are easiest to attain due to generous activity limits, but it cannot be expected that all fusion waste will be disposed of in Japan.

It is highly unlikely that all fusion reactors will be constructed of the same materials and be subject to the same disposal regulations. As such future fusion reactor design and operation planning 
should be influenced by decommissioning and disposal to a greater degree. It may also be justified to define fusion specific waste criteria and repositories. These should not replace internationally accepted standards, but it could allow the expected level of waste from fusion can be disposed of in a consistent manner: most likely as a mixture of ILW and LLW.

There are possibilities to improve the waste prospect for some fusion steels. Much of the long lived activation is a result of reactions on impurities in the steel [3], lowering the amount of impurities from nuclear grade steels would improve waste prospects, but if such modification could be transferred to mass production is yet to be determined. As table 3 shows, some steels can be LLW on the required timescales, so there is scope for materials development. This study has neglected the possibility of post-processing of the steels before disposal, techniques which remove tritium [22] and carbon [23] from steels have been proposed. How well these approaches are suited to large quantities of highly activated material has not been fully explored, but they show possibilities of how the amount of activated material from fusion facilities maybe reduced.

\section{ACKNOWLEDGEMENTS}

This work has been carried out within the framework of the EUROfusion Consortium and has received funding from the Euratom research and training programme 2014-2018 under grant agreement No. 633053 and from the RCUK Energy Programme (grant number EP/T012250/1). The views and opinions expressed herein do not necessarily reflect those of the European Commission. To obtain further information on the data and models underlying this paper please contact PublicationsManager@ukaea.uk.

\section{REFERENCES}

[1] M. R. Gilbert, T. Eade, C. Bachmann, U. Fischer, and N. P. Taylor. "Activation, Decay Heat, and Waste Classification Studies of the European DEMO Concept." Nucl Fusion, volume 57, p. 046015 (2017).

[2] M. R. Gilbert, T. Eade, C. Bachmann, U. Fischer, and N. P. Taylor. "Waste assessment of European DEMO fusion reactor designs." Fus Eng Des, volume 136, pp. 42-48 (2018).

[3] M. R. Gilbert, T. Eade, T. Rey, R. Vale, C. Bachmann, U. Fischer, and N. P. Taylor. "Waste implications from minor impurities in European DEMO materials." Nucl Fus, volume -, pp. (2019).

[4] J. -Ch. Sublet, J. W. Eastwood, J. G. Morgan, M. R. Gilbert, M. Fleming, and W. Arter. "FISPACT-II: An Advanced Simulation System for Activation, Transmutation and Material Modelling." Nucl Data Sheets, volume 139, pp. 77-137 (2017).

[5] A. J. Koning, D. Rochman, and J. -Ch. Sublet. “TENDL-2017.” Release Date: December 30, 2017. Available from https://tendl.web.psi.ch/tendl \_2017/tendl2017.html.

[6] Department for Business, Energy and Industrial Strategy. UK Radioactive Waste Inventory (2019). URL https://ukinventory.nda.gov.uk/about-radioactive-waste/what-is-radioactivity/ what-are-the-main-waste-categories/.

[7] N. D. Authority. "Ingrated Waste Management: Radioactive Waste Strategy." Technical report, Department for Business, Energy and Industrial Strategy (2018). 
[8] Elena Vico del Cerro. "GESTIÓN DE RESIDUOS RADIACTIVOS: Lección 15: Caracterización de residuos. I+D asociados." Technical report, MINISTERIO DE CIENCIA E INNOVACIÓN (2009).

[9] Federal Environemtal, Industrial and Nuclear Supervision Service of Russia. "Disposal of Radioactive Waste: Principles, Criteria and Basic Safety Requirements." Technical report, Federal Standards and Rules in the field of Atomic Energy (2004).

[10] A. Andrews. "Radioactive Waste Streams: Waste Classification for Disposal." CRS Report for Congress, Congressional Research Service (2006).

[11] U.S. Department of Energy. "U.S. Sixth National Report for the Joint Convention on the Safety of Spent Fuel Management and on the Safety of Radioactive Waste Management." Technical report (2017).

[12] Joint Convention on the Safety of Spent Fuel Management and on the Safety of Radioactive Waste Management. "National Report of Japan for the Fifth Review Meeting." Technical report, Nuclear Regulation Authority (2014).

[13] "Eurofer Steel, Development to Full Code Qualification.” Procedia Engineering, volume 55, pp. $300-308$ (2013).

[14] S. Möller, B. Kuhn, R. Rayaprolu, S. Heuer, M. Rasinski, and A. Kreter. "HiperFer, a reduced activation ferritic steel tested for nuclear fusion applications." Nuclear Materials and Energy, pp. 9 - 14 (2018).

[15] A. Golubeva, N. Bobyr, D. Cherkez, A. Spitsyn, M. Mayer, Y. Gasparyan, V. Efimov, V. Chernov, and M. Leontieva-Smirnova. "Hydrogen interaction with the low activation ferritic-martensitic steel EK-181 (Rusfer)." Journal of Nuclear Materials, volume 438, pp. S983 - S987 (2013).

[16] Q. Huang. "Development status of CLAM steel for fusion application." Journal of Nuclear Materials, volume 455, pp. 649 - 654 (2014).

[17] A. Kohyama, A. Hishinuma, D. Gelles, R. Klueh, W. Dietz, and K. Ehrlich. "Low-activation ferritic and martensitic steels for fusion application." Journal of Nuclear Materials, volume 233-237, pp. 138 - 147 (1996).

[18] A. Hishinuma, A. Kohyama, R. Klueh, D. Gelles, W. Dietz, and K. Ehrlich. "Current status and future R\&D for reduced-activation ferritic/martensitic steels." Journal of Nuclear Materials, volume 258-263, pp. 193 - 204 (1998).

[19] C. J. Werner et.al. "MCNP Users Manual - Code Version 6.2." Technical Report report LA-UR-17-29981, Los Alamos National Laboratory (2017).

[20] C. J. Werner et.al. "MCNP6.2 Release Notes." Technical Report report LA-UR-18-20808, Los Alamos National Laboratory (2018).

[21] Christian Bachmann et.al. "Initial DEMO tokamak design configuration studies." Fusion Engineering and Design, volume 98-99, pp. 1423 - 1426 (2015).

[22] A. N. P. et.al. "Experimental Trials of Methods for Metal Detritiation for JET." Fusion Science and Technology, volume 52, pp. 84-99 (2007).

[23] L. D. Pace, T. Beone, A. D. Donato, P. Miceli, F. Macci, R. Piancaldini, and E. Zanin. "Feasibility studies of DEMO potential waste recycling by proven existing industrial-scale processes." Fusion Engineering and Design, volume 146, pp. 107 - 110 (2019).

\section{APPENDIX A. Steel Elemental Compositions}


Table 4: The elemental composition, by percentage weight, of the steels studied

\begin{tabular}{|c|c|c|c|c|c|c|}
\hline Element & XM19 & Inconel 718 & SS316 & Steel 660 & G91-t1 & G91-t2 \\
\hline $\mathrm{Fe}$ & 56.26068 & 17.73411 & 63.684 & 52.2163 & 87.34 & 87.544 \\
\hline $\mathrm{Al}$ & & 0.5 & - & 0.350002 & 0.02 & 0.02 \\
\hline As & - & & - & & - & 0.01 \\
\hline B & - & 0.006 & 0.001 & 0.01 & - & 0.001 \\
\hline $\mathrm{C}$ & 0.059305 & 0.08 & 0.03 & 0.079074 & 0.12 & 0.12 \\
\hline Co & 0.05 & 0.1 & 0.05 & 0.200002 & - & - \\
\hline $\mathrm{Cr}$ & 22.0001 & 19.00018 & 18 & 14.75017 & 9.5 & 9.5 \\
\hline $\mathrm{Cu}$ & & 0.300001 & 0.3 & - & - & 0.1 \\
\hline $\mathrm{Mn}$ & 4.999998 & 0.35 & 2 & 2.000011 & 0.6 & 0.5 \\
\hline Mo & 2.25 & 3.000009 & 2.7 & 1.250011 & 1.05 & 1.05 \\
\hline $\mathrm{N}$ & 0.300011 & - & 0.08 & - & 0.07 & 0.07 \\
\hline $\mathrm{Nb}$ & 0.299999 & 5.100016 & 0.01 & 0.100001 & 0.1 & 0.1 \\
\hline $\mathrm{Ni}$ & 12.49993 & 52.49996 & 12.5 & 25.50009 & 0.4 & 0.2 \\
\hline $\mathrm{P}$ & 0.04 & 0.015 & 0.025 & 0.04 & 0.02 & 0.02 \\
\hline S & 0.03 & 0.015 & 0.01 & 0.03 & 0.01 & 0.005 \\
\hline $\mathrm{Sb}$ & - & - & - & - & - & 0.03 \\
\hline $\mathrm{Sn}$ & & - & . & - & - & 0.01 \\
\hline $\mathrm{Si}$ & 0.999987 & 0.349996 & 0.5 & 0.999994 & 0.5 & 0.4 \\
\hline $\mathrm{Ta}$ & 0.01 & 0.05 & 0.01 & 0.05 & - & \\
\hline $\mathrm{Ti}$ & & 0.899723 & 0.1 & 2.124361 & 0.01 & 0.01 \\
\hline V & 0.19999 & - & - & 0.299988 & 0.25 & 0.25 \\
\hline W & & . & - & - & & 0.05 \\
\hline $\mathrm{Zr}$ & - & - & - & - & 0.01 & 0.01 \\
\hline Element & Eurofer & Hiperfer & CLAM & Rusfer & F82H & \\
\hline $\mathrm{Fe}$ & 88.248 & 75.1 & 88.739 & 86.0183 & 89.3312 & \\
\hline $\mathrm{Al}$ & 0.01 & 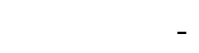 & - & 0.003 & 0.01 & \\
\hline $\mathrm{Ag}$ & - & - & - & - & 0.002 & \\
\hline As & 0.05 & - & - & - & 0.002 & \\
\hline B & 0.002 & - & - & 0.006 & 0.0003 & \\
\hline $\mathrm{C}$ & 0.11 & 0.02 & 0.1 & 0.15 & 0.1 & \\
\hline Co & 0.01 & 0.0067 & - & - & 0.005 & \\
\hline $\mathrm{Cr}$ & 9.0 & 16.5 & 8.76 & 11.17 & 8.0 & \\
\hline $\mathrm{Cu}$ & 0.01 & & & 0.01 & 0.01 & \\
\hline $\mathrm{Mn}$ & 0.4 & 0.186 & 0.42 & 0.74 & 0.1 & \\
\hline Mo & 0.005 & & - & 0.01 & 0.001 & \\
\hline $\mathrm{N}$ & 0.03 & 0.004 & 0.04 & 0.04 & 0.005 & \\
\hline $\mathrm{Nb}$ & 0.005 & 1.0 & - & 0.01 & 0.00005 & \\
\hline $\mathrm{Ni}$ & 0.01 & 0.0081 & . & 0.03 & 0.03 & \\
\hline $\mathrm{O}$ & 0.01 & 0.005 & 0.006 & - & 0.005 & \\
\hline $\mathrm{P}$ & 0.005 & & 0.1 & 0.001 & 0.005 & \\
\hline $\mathrm{S}$ & 0.005 & 0.01 & 0.005 & 0.006 & 0.002 & \\
\hline $\mathrm{Sb}$ & 0.05 & - & - & & 0.0005 & \\
\hline $\mathrm{Sn}$ & 0.05 & - & - & 0.0057 & 0.001 & \\
\hline $\mathrm{Si}$ & 0.05 & 0.3 & 0.05 & 0.33 & 0.1 & \\
\hline $\mathrm{Ta}$ & 0.12 & - & 0.16 & 0.08 & 0.04 & \\
\hline $\mathrm{Ti}$ & 0.02 & - & - & - & 0.05 & \\
\hline V & 0.2 & - & 0.22 & 0.25 & 0.2 & \\
\hline W & 1.1 & 4.2 & 1.4 & 1.13 & 2.0 & \\
\hline $\mathrm{Zr}$ & 0.05 & . & . & . & 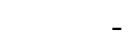 & \\
\hline
\end{tabular}

